\title{
Desaguamento de lodo de efluente saneante domissanitário em Leito de Drenagem
}

\section{Dewatering of wastewater household cleaning sanitizing sludge in Drainage Bed}

Data de entrada: 18/02/2016

Data de aprovação: $11 / 11 / 2016$

\section{Resumo}

Neste trabalho foi avaliado o emprego de Leitos de Drenagem (LD) no desaguamento de lodo proveniente do tratamento de efluente saneante domissanitário. Para composição dos LD foram avaliadas, preliminarmente, 16 mantas geotêxteis, em função da turbidez do efluente drenado e do tempo de drenagem, das quais três foram selecionadas para compor sua base: RT-26, RT-16 e RT-31 da BIDIM, ambas de tecido não agulhado, de filamentos contínuos, $100 \%$ poliéster. $O$ desempenho dos LD foi avaliado comparando-se a qualidade do efluente drenado e do tempo de secagem do lodo para diferentes Taxas de Aplicação de Sólidos (TAS): 1,75 $\mathrm{kg} \cdot \mathrm{m}^{-2}, 3,5 \mathrm{~kg} \cdot \mathrm{m}^{-2}$ e $7,0 \mathrm{~kg} \cdot \mathrm{m}^{-2}$. Os melhores resultados foram obtidos para o sistema composto pelo geotêxtil RT-31, em que o teor de sólidos na fase de secagem foi de 13\% a 16\%. Apesar de os valores de eficiência observados serem inferiores aos obtidos tratando-se lodos provenientes de Estações de Tratamento de Água e de Esgoto convencionais, é possível afirmar que o sistema pode ser aplicado, com eficiência, também para o condicionamento de lodo gerado em sistemas de tratamento de efluente saneante domissanitário. Palavras-chave: Leitos de Drenagem. Saneante Domissanitário. Tratamento de Lodo.

\section{Abstract}

In this work the use of Drenaige Beds (DB) in the sludge dewatering from the treatment of household cleaning sanitizing effluent was evaluated. For composition of DB were evaluated, preliminarily, 16 geotextiles plaids, depending on the turbidity of the effluent drained and drainage time, of which three were selected to compose the base: RT-26, RT-16 and RT-31 of BIDIM, both needled non-woven, of continuous filament, $100 \%$ polyester. The performance of $D B$ was evaluated by comparing the quality of the drained effluent and the drying time of sludge for different Solid Application Rates (RAS): 1,75 kg. $\mathrm{m}^{-2}, 3,5 \mathrm{~kg} \cdot \mathrm{m}^{-2}$ and 7,0 kg. $\mathrm{m}^{-2}$. The best results were obtained for the system composed by RT-31 geotextile, wherein the solds content in the drying stage was $13 \%$ to $16 \%$. Although the efficiency values observed were lower than those obtained by sludge treatment from Water Treatment Plants and of Wastewater Conventionals, we can say that the system can be applied, efficiently, also for the conditioning of sludge conditioning generated in household cleaning sanitizing treatment systems. Keywords: Draining Beds. Household Cleaning Sanitizing. Sludge Treatment.

\footnotetext{
Alessandra da Silva Oliveira* - Graduada em Engenharia Ambiental pela Universidade Federal de Uberlândia (UFU). Mestranda em Engenharia Civil pela Universidade Federal de Uberlândia (UFU). E-mail: alessandrasilvaolivayahoo.com.br.

André Luiz de Oliveira - Graduado em Engenharia Civil pela Universidade Federal de Viçosa (UFV). Mestre e doutor em Engenharia Hidráulica e Saneamento pela Universidade de São Paulo (USP). Professor Doutor da Universidade Federal de Uberlândia - Faculdade de Engenharia Civil (FECIV/UFU).

*Endereço para correspondência: Avenida João Naves de Ávila, 2121 - Bloco 1Y - Santa Mônica - Uberlândia - Minas Gerais - CEP: $38400-902$. Telefone: (34) 99196-3052.
} 


\section{INTRODUÇÃO}

Saneantes domissanitários compreendem-se por substâncias ou preparações destinadas à higienização, desinfecção, desinfestação, desodorização e odorização de ambientes domiciliares, coletivos e/ ou públicos, para fins domésticos ou profissionais. Durante seu processo de fabricação, há utilização de água na incorporação ao produto, lavagem de máquinas, tubulações e pisos, bem como o uso direto nas etapas do processo industrial, ou seja, geração de efluentes que são ricos em tensoativos e saneantes que podem ser tratados por processos físico-químicos, bem como por processos oxidativos avançados ou por meio de tratamento biológico (PERES, 2005).

Ao final de qualquer técnica de tratamento do efluente saneante domissanitário, uma grande escala de lodo é gerada. Embora, segundo a ABNT NBR 10.004 (2004), ele seja classificado como resíduo sólido, apresenta uma elevada parcela em termos de volume na fase líquida (em torno de $92 \%$ ) e, portanto, requer tratamento, consistindo na remoção de água livre e intersticial, objetivando redução de volume, facilidade no manuseio, transporte e disposição final adequada (LOPES, 2005).

Diferentes tecnologias podem ser empregadas no desaguamento do lodo, como o uso de espessadores (sedimentadores e flotadores); sistemas mecânicos (centrífugas, filtros-prensa, prensas desaguadoras e filtros à vácuo); e sistemas naturais (lagoas de lodo, leitos de secagem, leitos de drenagem). A seleção da técnica adequada é condicionada a disponibilidade financeira, fatores climáticos e área disponível, en- tre outras variáveis dependentes das características e exigências do resíduo. Portanto, antes da implantação em escala industrial, a realização de um estudo em escala piloto é de fundamental importância (FONTANA, 2004; ACHON et al., 2008).

Os sistemas naturais de tratamento de lodo apresentam vantagens em relação aos mecânicos, visto que os custos de implantação, operação e manutenção são menores, além de constituírem alterativas ambientalmente favoráveis pela economia de energia e pela simplicidade de operação. Entretanto, como o mecanismo de desaguamento consiste na evaporação e na percolação da água presente no lodo, a disponibilidade de área e as condições climáticas (precipitação, umidade do ar, irradiação solar e temperatura ambiente) são fatores limitantes para sua aplicação.

No Brasil, a utilização de sistemas naturais de desaguamento de lodos é favorecida pelas condições vantajosas de espaço e condições climáticas adequadas em diversas regiões. Os LD consistem de uma pequena modificação na base dos Leitos de Secagem a partir das pesquisas de Cordeiro (2001), objetivando o aumento da eficiência. Em diversos trabalhos, como os conduzidos por Fontana (2004), Barroso (2007), Fontana et al. (2007) e Mortara (2011), a alteração da estrutura física do leito de secagem tradicional, por meio da substituição total da areia do meio filtrante pela manta geotêxtil e redução da altura da camada de brita, conforme ilustrado na Figura 1, capacitou o aumento na velocidade de retirada da água livre do lodo e melhoria da qualidade do drenado.

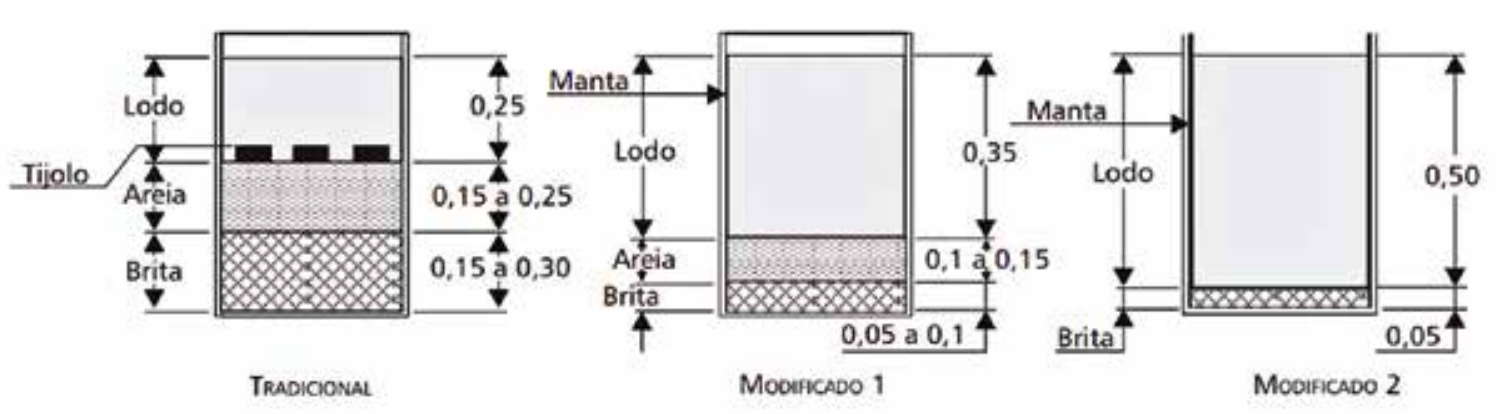

Figura 1 - Leitos de secagem tradicional e modificados (Cordeiro, 2001) 
Inicialmente, o princípio de funcionamento do desaguamento em sistemas naturais é a ação da gravidade na retirada de água, que escoa entre os poros do meio filtrante e é removida do lodo. Conforme a carga sobre o filtro e o percentual de água livre são reduzidos, e à medida em que ocorre deposição de partículas de sólidos sobre o filtro, os poros da manta são colmatados e, assim, a taxa de retirada da água livre é reduzida. Ao final da drenagem, a evaporação passa a ser o principal processo responsável pela secagem do lodo (CORDEIRO, 2001).

A aplicação dos LD no tratamento de lodos de Estações de Tratamento de Água (ETAs) tem comprovada eficiência com vantagens sobre os leitos de secagem, como melhor qualidade do drenado e maiores TAS, indicando seu uso em escala real (BARROSO, 2007; ACHON et al., 2008; SANTOS, 2012; SILVEIRA, 2012). Kuroda et al. (2013) verificaram que, independentemente da TAS aplicada, a turbidez de uma amostra global, constituída por toda a água drenada em um sistema de leito de drenagem composto por uma manta geotêxtil com densidade de $600 \mathrm{~g} \cdot \mathrm{m}^{-2}$, atendeu às condições de lançamento para um corpo d'água de Classe II. Nesse mesmo estudo foi comprovado também que o desaguamento do lodo por esse método reduziu consideravelmente a quantidade de metais nos drenados, bem como a toxicidade destes. Silveira (2012), que também desenvolveu um estudo de desaguamento de lodo de ETA por meio de protótipos de leitos de drenagem em escala reduzida, verificou que a qualidade água drenada pelo sistema foi compatível com o enquadramento de corpos d'água de Classes I e II estabelecidos pela Resolução 357/2005 do Conama, possibilitando até mesmo o reaproveitamento dessa água na produção de água tratada na própria ETA.
Nesse contexto, o presente trabalho foi desenvolvido com o objetivo de estudar o sistema de desaguamento do lodo proveniente de uma indústria de produtos saneantes domissanitários em sistemas de leito de drenagem, visando à aceleração dos processos de drenagem e secagem do lodo, por meio da avaliação de diferentes mantas geotêxteis, considerando diferentes taxas de aplicação de sólidos, possibilitando, assim, a comparação entre as mesmas.

\section{MATERIAL E MÉTODOS}

\subsection{Origem, coleta e preservação das amostras} de lodo

O lodo utilizado no desaguamento foi coletado na Estação de Tratamento de Efluente (ETE) de uma indústria de saneantes domissanitários no município de Uberlândia (MG), logo após sua sedimentação no tanque, por meio de canalização de distribuição para os leitos de secagem. O tratamento físico-químico do lodo era realizado empregando policloreto de alumínio 4\% como coagulante primário, correção do $\mathrm{pH}$ com cal hidratada e aplicação de polímero à base de poliacrilamida (PCA). Após o tratamento, o efluente era encaminhado ao sistema de coleta e afastamento de esgotos do DMAE (Departamento Municipal de Água e Esgoto) e o lodo sedimentado até o leito de secagem, onde posteriormente era armazenado em caçambas para então ser encaminhado ao aterro industrial (Figura 2).

Para condução dos experimentos, eram coletados 100 I de lodo e, em laboratório, a amostra era transferida para um único recipiente de $250 \mathrm{l}$, facilitando a equalização do lodo para a execução dos ensaios. Primeiramente, o lodo foi caracterizado quanto ao teor de sólidos totais, seguindo o método gravimétrico descrito na NBR 10.664 (1989). 


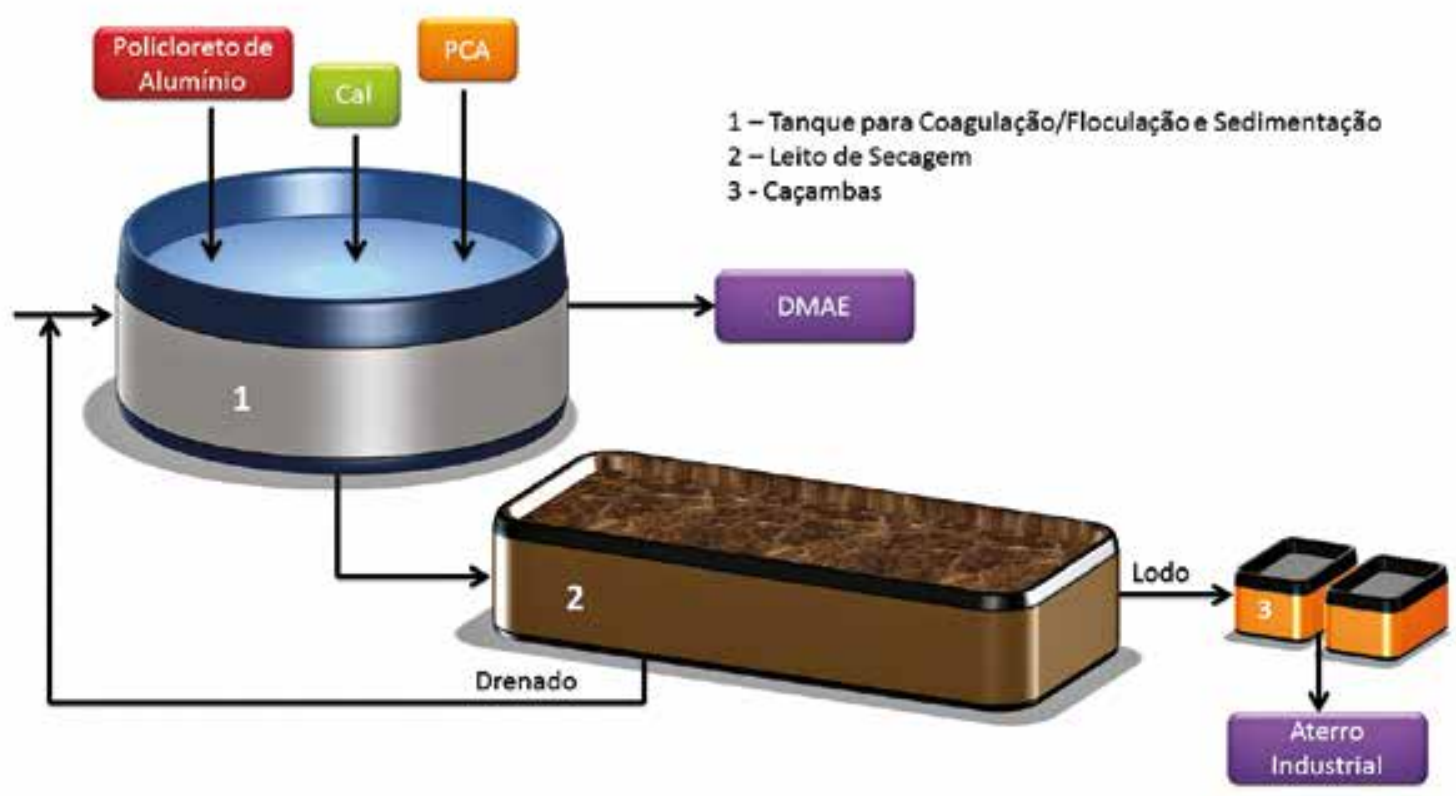

Figura 2 - Sistema de tratamento do efluente industrial

\subsection{Ensaios de avaliação das mantas geotêxteis}

Com a finalidade de proporcionar uma melhor eficiência em termos de velocidade de drenagem e qualidade do drenado, foram testadas 16 mantas geotêxteis de duas marcas diferentes (MACCAFERRI e BIDIM), conforme a Tabela 1, para então selecionar as mais favoráveis para composição dos LD.

Tabela 1 - Mantas geotêxteis avaliadas

\begin{tabular}{|c|c|c|c|}
\hline $\begin{array}{c}\text { Característica } \\
\text { do Geotêxtil }\end{array}$ & Marca & Quantidade & Descrição \\
\hline $\begin{array}{c}\text { Tecido não } \\
\text { agulhado de } \\
\text { fllamentos } \\
\text { contínuos 100\% } \\
\text { poliéster }\end{array}$ & BIDIM & 6 & $\begin{array}{c}\text { RT-08, RT-14, } \\
\text { RT-16, RT-21, } \\
\text { RT-26, RT-31 }\end{array}$ \\
\hline $\begin{array}{c}\text { Tecido não } \\
\text { agulhado de } \\
\text { polipropileno }\end{array}$ & MACCAFERRI & 4 & $\begin{array}{c}\text { N26.1, N40.1, } \\
\text { N30.1 }\end{array}$ \\
\hline $\begin{array}{c}\text { Tecido não } \\
\text { agulhado de } \\
\text { poliéster }\end{array}$ & MACCAFERRI & & N20.2, N26.2, \\
\hline
\end{tabular}




\subsection{Ensaios experimentais nos protótipos dos Leitos de Drenagem}

Os LD utilizados eram compostos por tubo de PVC de $150 \mathrm{~mm}$ de diâmetro, 0,5 $\mathrm{m}$ de altura, base com CAP de PVC de diâmetro de $150 \mathrm{~mm}$, onde a manta geotêxtil era posicionada, apoiada sobre o leito de brita e registro de esfera para coleta das amostras. $O$ desempenho do sistema foi avaliado na fase de drenagem e fase de secagem.

$\mathrm{Na}$ fase de drenagem, as amostras de lodo eram homogeneizadas para que o lodo mantivesse a concentração de sólidos em qualquer ponto da amostra. Após a aplicação do lodo nos protótipos, aferiram-se os volumes do drenado nos tempos de $15,30,45,60,90,120$ min e depois a cada $90 \mathrm{~min}$ até o fim da fase de drenagem. Neste trabalho, o fim da fase de drenagem se deu após a extinção da lâmina líquida de lodo, como em Silveira et al. (2011). Ressalta-se que outros autores, como Barroso (2007), consideram que o fim da fase de drenagem ocorre ao cessar a drenagem de água livre, ou quando a vazão de drenagem for inferior a 1,67 10 $0^{-2}$ I. $\mathrm{min}^{-1}$. Os drenados coletados nos tempos pré-determinados foram caracterizados quanto ao volume, vazão, percentual de volume de drenado em função do tempo, cor verdadeira, cor aparente e turbidez.

Foram avaliadas três Taxas de Aplicação de Sólidos (TAS): 1,75 kgST.m $\mathrm{m}^{-2}, 3,5 \mathrm{kgST} . \mathrm{m}^{-2}$ e 7,0 kgST.m ${ }^{-2}$. 0 cálculo do volume necessário para atingir essas taxas foi realizado conforme a Equação 1.

$V=\left(T A S \cdot A_{f}\right) / S T$

Onde: $\mathrm{V}=$ Volume de lodo aplicado ao sistema (l); ST = Concentração de sólidos totais do lodo $\left(\mathrm{kg} . \mathrm{l}^{-1}\right) ; \mathrm{A}_{\mathrm{f}}=$ Área da base do protótipo do leito de drenagem $\left(\mathrm{m}^{2}\right)$.

Assim que cessada a fase de drenagem, a fase de secagem era iniciada. $O$ desempenho dos LD nessa fase foi averiguado quanto à caracteri- zação diária do teor de sólidos do lodo retido no geotêxtil, por sete dias consecutivos (BARROSO, 2007; SILVEIRA et al., 2011). Como nessa fase do ensaio o lodo foi submetido totalmente às condições climáticas do local, foram avaliadas também as possíveis influências dessas variáveis, incluindo temperatura $\left({ }^{\circ} \mathrm{C}\right)$, umidade ambiente $(\%)$, radiação solar (100 kJ.m $\left.\mathrm{m}^{-2}\right)$, velocidade do vento $\left(\mathrm{m} . \mathrm{s}^{-1}\right)$ e pluviosidade $(\mathrm{mm})$. Neste trabalho, a média dos valores foi calculada a partir de valores instantâneos no intervalo de 24 horas anteriores ao horário de coleta durante o intervalo de sete dias (ACHON, et al., 2008).

\section{RESULTADOS E DISCUSSÃO}

\subsection{Lodo de estudo}

A concentração de sólidos totais da amostra de lodo foi equivalente a $15.685 \mathrm{mg.l}^{-1}$. Conforme a Resolução Conama 430/2011, que dispõe sobre as condições e padrões de lançamento de efluente, o limite de sólidos dissolvidos totais que podem ser lançados diretamente em cursos d'água de Classe Il é de $500 \mathrm{mg} . \mathrm{l}^{-1}$. Além disso, a Deliberação Normativa Conjunta Copam/CERH-MG n 01/2008 também estabelece um limite de $100 \mathrm{mg}^{-1} \mathrm{de}$ sólidos em suspensão totais. Consequentemente, não há dúvidas de que o lançamento desses lodos in natura resultaria em impactos negativos para cursos d'água.

\subsection{Escolha das mantas geotêxteis}

Devido aos resultados extremos de $1^{\circ}$ e $2^{\circ}$ Tempo de Drenagem (TDD) e/ou $1^{\circ}$ e $2^{\circ}$ valores de turbidez (Tabela 2) obtidos nos ensaios de quatro mantas geotêxteis, estes foram retirados do cálculo da média, já que este foi o parâmetro considerado na seleção dos geotêxteis a comporem os protótipos. A manutenção desses resultados poderia interferir negativamente na escolha das melhores mantas a serem utilizadas, uma vez que a média pode não ser representativa quando da existência de valores extremos. Os demais resultados são apresentados na Tabela 3. 
A partir desses resultados é possível notar que a média do TDD aumentou cinco vezes, já que o $1^{\circ}$ e $2^{\circ}$ TDD médios foram de 180 s e $1051 \mathrm{~s}$, respectivamente; e a turbidez, em média foi reduzida em duas vezes ( $1^{\text {a }}$ turbidez média igual a 2192 UNT, e $2^{\text {a }}$ turbidez de 1057 UNT). 0 geotêxtil RT-21 foi o que apresentou menor tempo de drenagem, enquanto que N30.1 e N40.1 apresentaram os maiores tempos. Infere-se que esse comportamento pode ser explicado pelo tipo de material de composição do geotêxtil (não-tecido em propileno) que não é favorável à velocidade de drenagem e à qualidade do drenado para este tipo de lodo.

Tabela 2 - Mantas Geotêxteis não utilizadas para o cálculo da média por apresentarem valores extremos de TDD e/ou Turbidez

\begin{tabular}{|c|c|c|c|c|}
\hline Manta & $\mathbf{1}^{\mathbf{0}}$ TDD (s) & $\begin{array}{c}\mathbf{1}^{\mathbf{a}} \text { Turbidez } \\
\text { (UNT) }\end{array}$ & $\mathbf{2}^{\mathbf{0}}$ TDD (s) & $\begin{array}{c}\mathbf{2}^{\mathbf{a}} \text { Turbidez } \\
\text { (UNT) }\end{array}$ \\
\hline RT-21 & 16 & 2112,000 & 191 & 1320,000 \\
\hline N26.1 & 39 & 3012,000 & 1780 & 784,000 \\
\hline N40.1 & 421 & 1661,333 & 2736 & 668,000 \\
\hline N30.1 & 542 & 2212,000 & 3613 & 922,667 \\
\hline
\end{tabular}

Tabela 3 - Valores do $1^{\circ}$ TDD e $1^{\text {a }}$ Turbidez dos primeiros $50 \mathrm{ml}$ de drenado, e $2^{\circ}$ TDD e $2^{\mathrm{a}}$ Turbidez para os próximos $50 \mathrm{ml}$ de drenado

\begin{tabular}{|c|c|c|c|c|}
\hline Manta & $\mathbf{1}^{\mathbf{0}}$ TDD (s) & $\begin{array}{c}\mathbf{1}^{\mathbf{a}} \text { Turbidez } \\
\mathbf{( U N T )}\end{array}$ & $\mathbf{2}^{\mathbf{0}}$ TDD (s) & $\begin{array}{c}\mathbf{2}^{\mathbf{a}} \text { Turbidez } \\
\text { (UNT) }\end{array}$ \\
\hline RT-26 & 104 & 1852,000 & 383 & 1084,000 \\
\hline RT-31 & 210 & 1700,000 & 541 & 1112,000 \\
\hline RT-08 & 84 & 2734,667 & 741 & 1102,667 \\
\hline RT-14 & 205 & 2341,333 & 954 & 1181,333 \\
\hline RT-16 & 114 & 2429,333 & 835 & 1165,333 \\
\hline N99.2 & 313 & 1974,667 & 1017 & 1117,333 \\
\hline N36.2 & 173 & 2280,000 & 1335 & 1001,333 \\
\hline N20.2 & 92 & 2084,000 & 1503 & 797,333 \\
\hline N80.2 & 240 & 2173,333 & 1071 & 1141,333 \\
\hline N60.2 & 209 & 2073,333 & 1212 & 1076,000 \\
\hline N40.2 & 360 & 2032,000 & 2085 & 876,000 \\
\hline N26.2 & 59 & 2634,667 & 941 & 1030,667 \\
\hline Média & 180,5 & 2192,444 & 1051,5 & 1057,111 \\
\hline & & & & \\
\hline
\end{tabular}

Com base nos resultados, foi possível selecionar três mantas geotêxteis para compor os protótipos de leitos de drenagem: RT-16, RT-26 e RT-31, todas da marca BIDIM, cujas especificações técnicas são descritas na Tabela 4.

Tabela 4 - Especificações técnicas dos geotêxteis selecionados para composição LD (BIDIM, 2014)

\begin{tabular}{|c|c|c|c|c|c|c|}
\hline \multirow[b]{2}{*}{ Manta } & \multicolumn{4}{|c|}{ PROPRIEDADES HIDRÁULICAS } & \multicolumn{2}{|c|}{ PROPRIEDADES FÍSICAS } \\
\hline & $\underset{\left(\mathbf{s}^{-1}\right)}{\mathrm{TG}}$ & $\begin{array}{l}\text { Fluxo de Água } \\
\left(1 \mathrm{~min}^{-1} \cdot \mathrm{m}^{-2}\right)\end{array}$ & $\begin{array}{c}\mathrm{K} \\
\left(\mathrm{cm} \cdot \mathrm{s}^{-1}\right)\end{array}$ & $\begin{array}{c}\text { Abertura } \\
\text { aparente (095) } \\
(\mathrm{mm}) \text { (Peneira) }\end{array}$ & $\begin{array}{l}\text { Matéria-prima } \\
\text { e tecnologia }\end{array}$ & $\begin{array}{l}\text { Ponto de Fusão } \\
\left({ }^{\circ} \mathrm{C}\right)\end{array}$ \\
\hline RT-26 & 0,8 & 2760 & 0,37 & $0,150(100)$ & \multirow{3}{*}{$\begin{array}{l}\text { 100\% poliéster- } \\
\text { filamentos } \\
\text { contínuos }\end{array}$} & 260 \\
\hline RT-16 & 1,3 & 4820 & 0,38 & $0,180(80)$ & & 260 \\
\hline RT-31 & 0,8 & 2340 & 0,37 & $0,125(120)$ & & 260 \\
\hline
\end{tabular}

A permissividade hidráulica (TG) permite avaliar a facilidade com que o fluido atravessa transversalmente o geotêxtil; a condutividade hidráulica (K) é um coeficiente de proporcionalidade da Lei de Darcy, que rege os movimentos dos fluidos em meios porosos e a abertura aparente (095) refere-se ao valor do diâmetro da maior partícula que passa pelos poros do geotêxtil (MORTARA, 2011; SANTOS, 2012).

\subsection{Ensaios experimentais nos protótipos dos Leitos de Drenagem}

\section{Fase de drenagem}

Os resultados dos percentuais de drenado acumulado para as TAS de 1,75 kg.m-2, 3,5 kg.m-2 e 7,0 kg.m-2 são mostradas respectivamente nas Figuras 3 , 4 e 5 . 


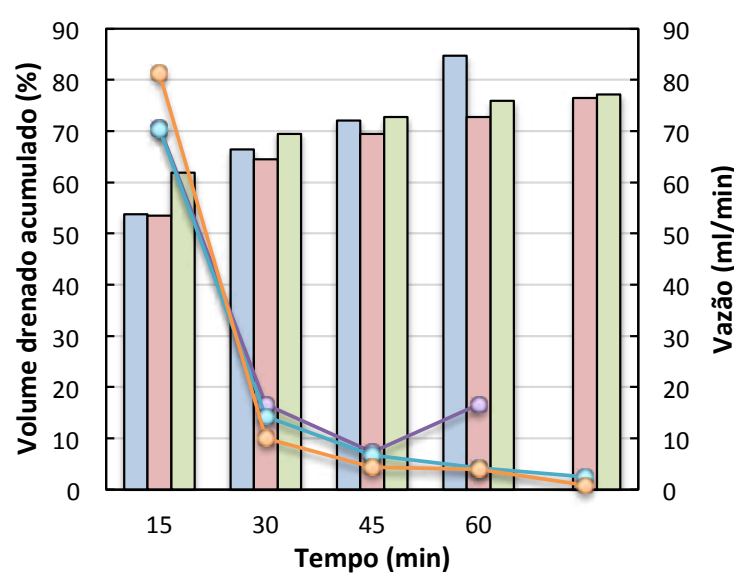

Figura 3 - TAS $=1,75 \mathrm{~kg} \cdot \mathrm{m}^{-2}$

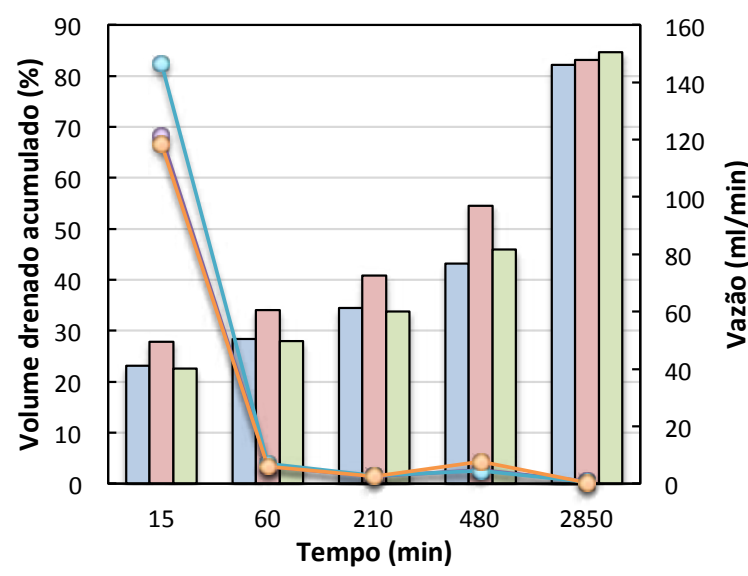

Figura 5 - TAS $=7,0 \mathrm{~kg} \cdot \mathrm{m}^{-2}$

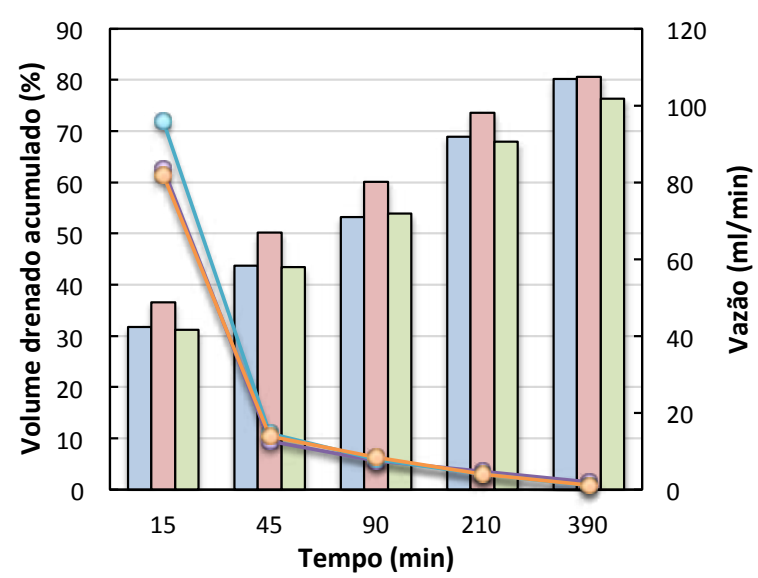

Figura 4 - TAS $=3,5 \mathrm{~kg} \cdot \mathrm{m}^{-2}$

\section{Legenda}

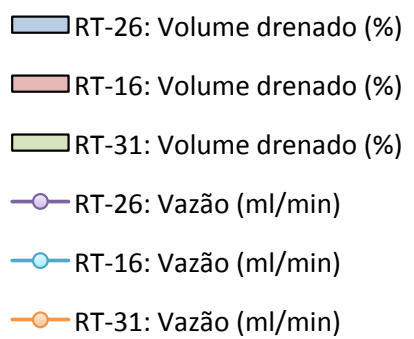

Enquanto o tempo gasto para a extinção da lâmina de água nos ensaios com TAS de 1,75 kg.m-2 foi de aproximadamente 60 minutos para a manta geotêxtil RT-26 e de 90 minutos para as mantas RT-16 e RT-31, para a TAS de 3,5 kg.m-2 foi de 6,5 h e para a de 7,0 kg.m-2 o tempo de drenagem foi de 47,5 h. Nota-se que independentemente da taxa de aplicação de sólidos, os resultados apresentaram uma relação inversa entre o volume de drenado acumulado e a vazão ao longo do tempo. Esse resultado era esperado, uma vez que à medida que os poros das mantas são obstruídos pela retenção de partículas de lodo a vazão de drenado é reduzida em função do tempo.

Os percentuais de volume de água livre drenada foram próximos para as três mantas geotêxteis (em torno de $80 \%$ ). Isso pode ser justificado pelas semelhanças nas propriedades hidráulicas das mesmas (fluxo de água, permissividade e condutividade hidráulica), descritas na Tabela 4.

São apresentadas nas Figuras 6, 7 e 8, os resultados das análises de cor e turbidez dos drenados para as três mantas selecionadas, em cada uma das TAS estudadas. 

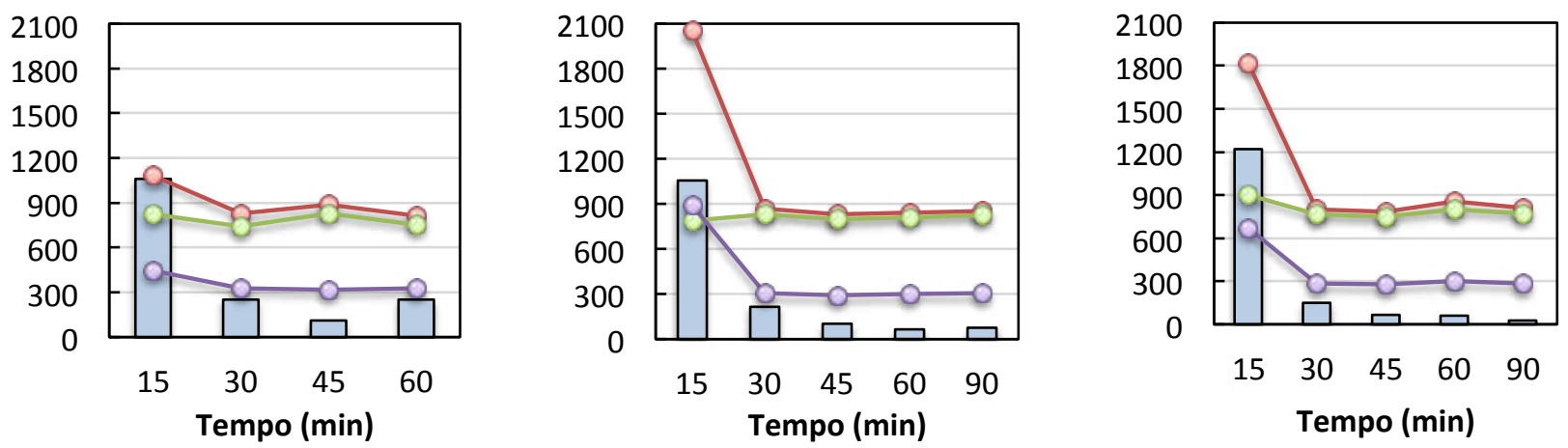

$\square$ Volume $(\mathrm{mL}) \quad-\mathrm{O}-$ Cor aparente $(\mathrm{uH})-\mathrm{O}-$ Cor verdadeira $(\mathrm{uH}) \quad \mathrm{O}-$ Turbidez (UNT)
a) RT-26
b) RT-16
c) RT-31

Figura 6 - Dados de volume, cor aparente, cor verdadeira e turbidez ao longo do tempo da fase de drenagem à TAS = 1,75 kg.m-2 para as mantas: (a) RT-26; (b) RT-16; e (c) RT-31
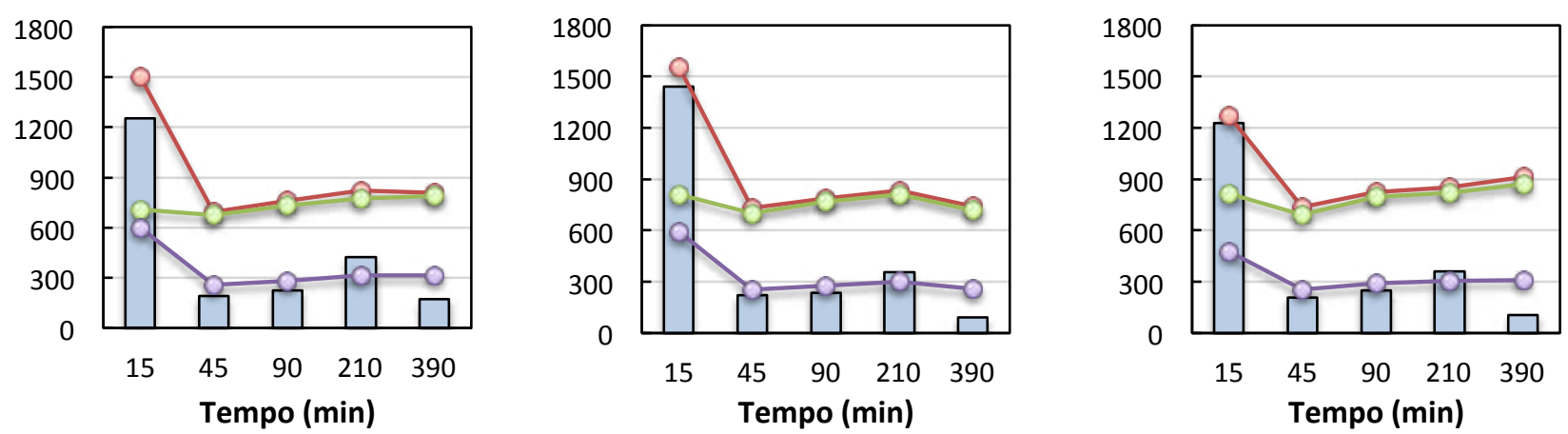

$\square$ Volume $(\mathrm{mL}) \quad \mathrm{O}-$ Cor aparente $(\mathrm{uH}) \longrightarrow \mathrm{O}-$ Cor verdadeira $(\mathrm{uH}) \longrightarrow \mathrm{O}$-Turbidez (UNT)
a) RT-26
b) RT-16
c) RT-31

Figura 7 - Dados de volume, cor aparente, cor verdadeira e turbidez ao longo do tempo da fase de drenagem à TAS = 3,5 kg.m-2 para as mantas: (a) RT-26; (b) RT-16; e (c) RT-31
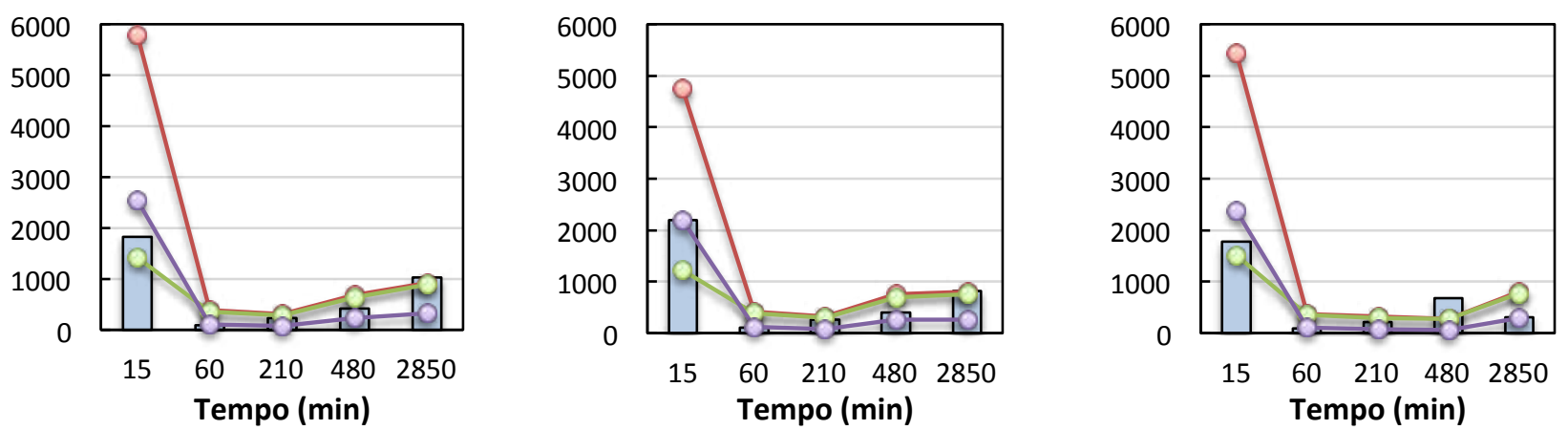

$\square$ Volume $(\mathrm{mL})$

$-\mathrm{O}-$ Cor aparente $(\mathrm{uH})$

$\longrightarrow-$ Cor verdadeira (uH)

$\longrightarrow$-Turbidez (UNT)

\section{a) RT-26}

b) RT-16

c) RT-31

Figura 8 - Dados de volume, cor aparente, cor verdadeira e turbidez ao longo do tempo da fase de drenagem à TAS = 7,0 kg.m-2 para as mantas: (a) RT-26; (b) RT-16; e (c) RT-31 
De modo geral, nos primeiros 15 minutos, a água drenada apresentou elevada cor e turbidez em todos os ensaios (considerando-se os valores obtidos posteriormente), enquanto que nas segundas coletas, correspondentes a 30 minutos após o início da drenagem, tais parâmetros apresentaram valores significativamente mais baixos. Para a TAS de 7,0 kg.m-2, apesar dos altos resultados de turbidez e cor verificados na amostra de drenado coletado aos 15 minutos, a redução foi de cerca de $90 \%$ para cor aparente, $65 \%$ para cor verdadeira e $92 \%$ para turbidez considerando-se a amostra de drenado coletado aos 30 minutos de ensaio. A clarificação do drenado está relacionada à retenção de partículas de lodo nas mantas, causando a obstrução dos poros, favorecendo a ação de "coar" do geotêxtil e em contrapartida diminuindo a vazão de drenado.

Para algumas amostras os volumes de drenado coletados em tempos posteriores foram relativamente maiores que os volumes obtidos nos tempos de coleta anteriores. Essa observação pode ser notada principalmente nos sistemas com TAS de 3,5 kg.m ${ }^{-2}$ e 7,0 kg.m ${ }^{-2}$, independentemente da manta geotêxtil de composição do LD. Uma explicação possível é que essa diferença tenha ocorrido pelo surgimento de caminhos preferenciais na manta de lodo e no próprio meio filtrante (manta), em função da menor disponibilidade de água livre, tendo como consequência, nessas situações, a deterioração da qualidade dos drenados.

Ao comparar os resultados de turbidez obtidos quando o sistema foi submetido à TAS de 1,75 $\mathrm{kg} \cdot \mathrm{m}^{-2}$ (Figura 6), foi possível observar que nos primeiros 15 minutos da fase de drenagem a manta
RT-26 foi a que apresentou melhor desempenho na qualidade do drenado, enquanto a RT-16 apresentou o pior desempenho. Já no sistema de leito de drenagem com TAS de 3,5 kg.m ${ }^{-2}$, entretanto, a qualidade da água drenada foi semelhante entre essas mesmas mantas (601 UNT para RT-26 e 592 UNT para RT-16), conforme a Figura 7. Por fim, a diferença de turbidez da água drenada no primeiro intervalo de tempo pré-determinado para todos os geotêxteis foi menor para o ensaio com TAS de 7,0 kg.m-2 (Figura 8). Apesar das diferenças entre a permissividade hidráulica e abertura aparente das mantas, constatadas na Tabela 4, a taxa de aplicação possui influência sobre as propriedades hidráulicas, visto que a porosidade e a abertura dos poros são afetadas, alterando assim o comportamento drenante do geotêxtil, sendo essa a possível causa da controversa nos resultados obtidos.

As Figuras 9, 10 e 11 apresentam as comparações dos resultados de turbidez e volume de drenado para cada um dos geotêxteis testados com diferentes TAS. Uma diferença significativa de turbidez é observada em todos os ensaios para a TAS de 7,0 $\mathrm{kg} \cdot \mathrm{m}^{-2}$ nos primeiros 15 minutos de drenagem. Já nos intervalos de tempo seguintes, os resultados foram reduzidos a valores inferiores aos drenados das demais taxas. Uma vez que a TAS é maior, a obstrução dos poros durante os primeiros $15 \mathrm{mi}-$ nutos também é maior, dificultando a passagem da água livre, e ao mesmo tempo melhorando a qualidade do drenado. A partir de 480 minutos, os valores desse parâmetro passam a ser semelhantes aos das demais taxas, em razão da redução do volume de água livre a ser drenada no LD e pelo aumento do volume de drenado coletado. 


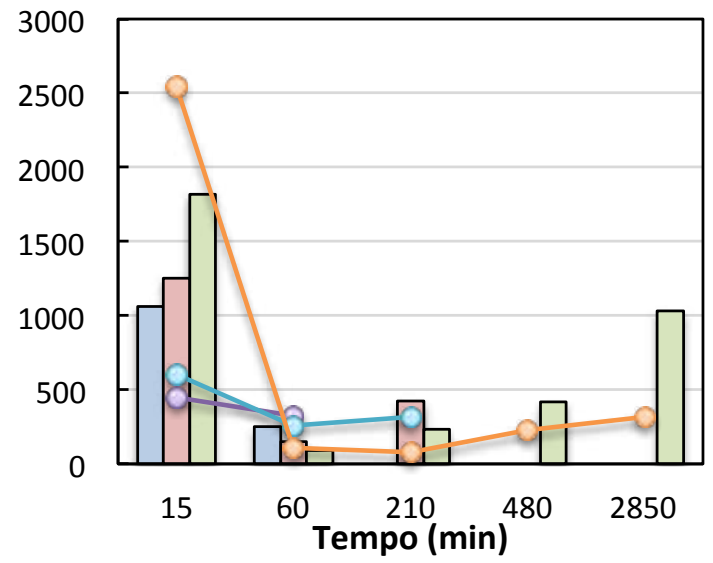

Figura 9 - Comparação entre as TAS de 1,75 $\mathrm{kg} \cdot \mathrm{m}^{-2}, 3,5 \mathrm{~kg} \cdot \mathrm{m}^{-2}$ e $7,0 \mathrm{~kg} \cdot \mathrm{m}^{-2}$ para RT-26

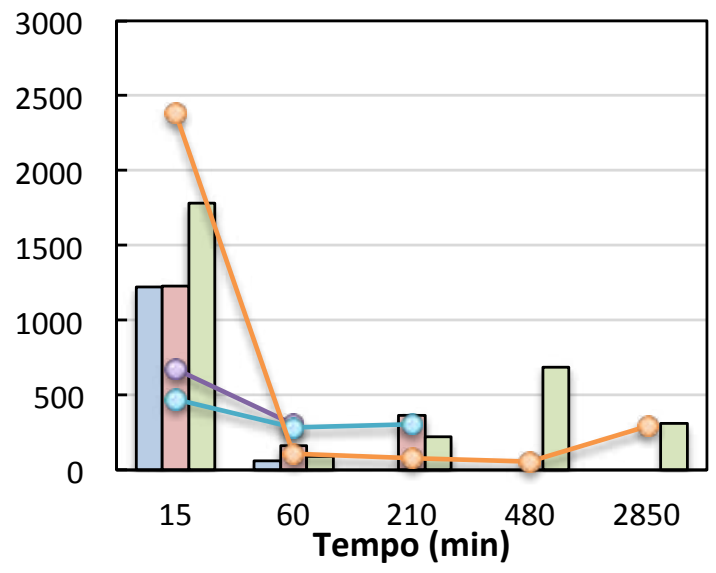

Figura 11 - Comparação entre as TAS de 1,75 $\mathrm{kg} \cdot \mathrm{m}^{-2}, 3,5 \mathrm{~kg} \cdot \mathrm{m}^{-2}$ e $7,0 \mathrm{~kg} \cdot \mathrm{m}^{-2}$ para RT-31

\section{Fase de secagem}

Assim que cessada a fase de drenagem, o lodo retido foi submetido totalmente à ação das variáveis climáticas (temperatura, umidade ambiente, orvalho, vento, irradiação solar e pluviosidade), iniciando, assim, a etapa de desidratação do material. De acordo com Achon et al. (2008), a velocidade do processo de desidratação está fundamentalmente relacionada a essas variáveis, visto que a evaporação é o principal fator responsável pela secagem.

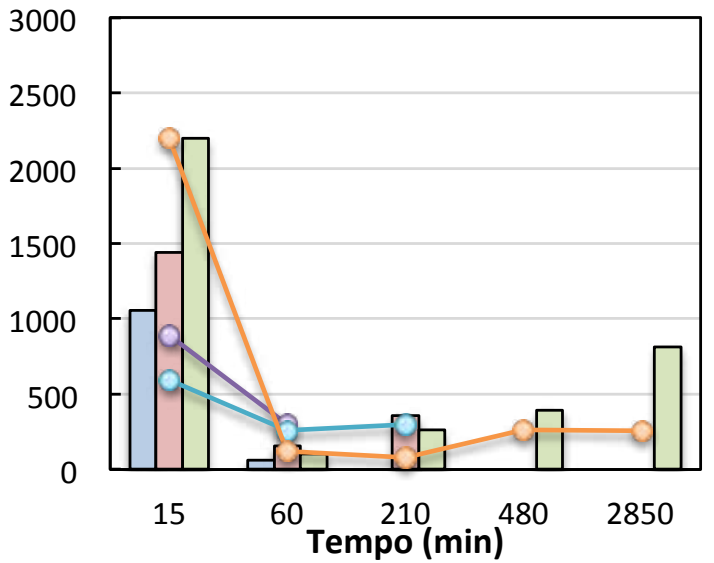

Figura 10 - Comparação entre as TAS de 1,75 $\mathrm{kg} \cdot \mathrm{m}^{-2}, 3,5 \mathrm{~kg} \cdot \mathrm{m}^{-2}$ e $7,0 \mathrm{~kg} \cdot \mathrm{m}^{-2}$ para RT-16

\section{Legenda}

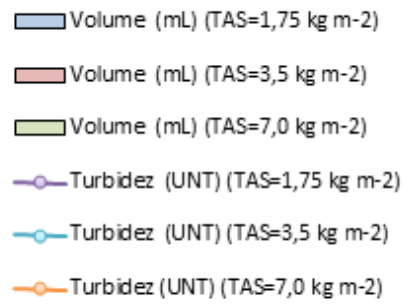

As Figuras 12, 13 e 14 apresentam os resultados diários obtidos para o teor de sólidos e variáveis climáticas avaliados na TAS de 1,75 kg.m ${ }^{-2}$ para os geotêxteis RT-26, RT-16 e RT-31, respectivamente. Por meio da variação diária do percentual de sólidos, é possível verificar a importância da ação das mesmas no processo de desidratação, a qual ocorre com mais facilidade em condições climáticas mais favoráveis (ausência de chuva, maiores temperaturas, maiores velocidades do vento). Isso pode ser verificado comparando-se os resultados da Figura 12 com as Figuras 13 e 14. Ao final da fase de secagem, 
foi obtido um teor de $13,5 \%$ de sólidos no ensaio da manta RT-26, ao passo que para as mantas RT-16 e RT-31, os teores foram de respectivamente, $15,2 \%$ e $16,4 \%$. Dentre as variáveis contribuintes para esse resultado, destacam se a umidade relativa do ar, cuja média durante o ensaio com geotêxtil RT-26 foi de $85,4 \%$, enquanto nos demais foi de $74,5 \%$; a tempe-

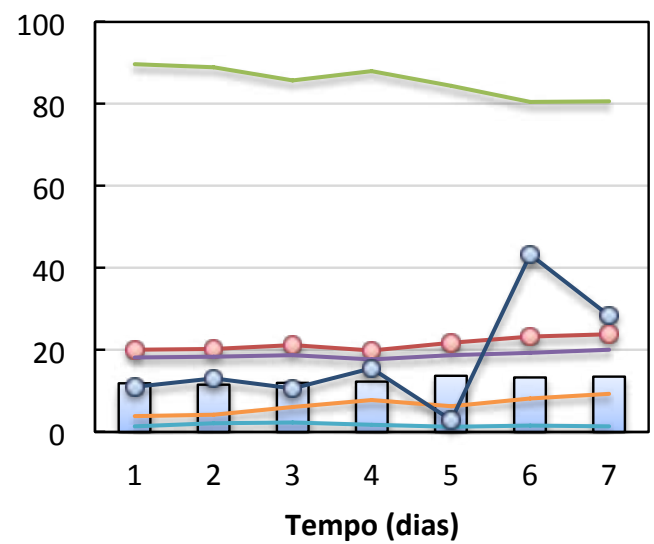

Figura 12 - Dados do teor de sólidos (\%) e médias diárias das variáveis climáticas para RT-26 com TAS $=1,75 \mathrm{~kg} \cdot \mathrm{m}^{-2}$

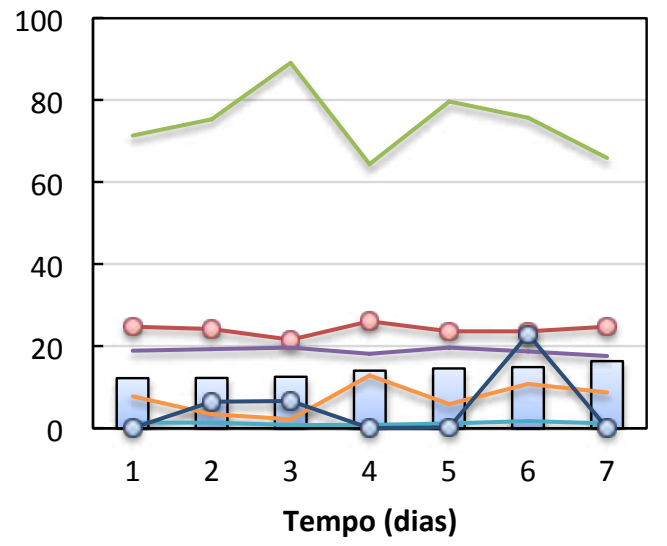

Figura 14 - Dados do teor de sólidos (\%) e médias diárias das variáveis climáticas para $\mathrm{RT}-31$, submetida à TAS $=1,75 \mathrm{~kg} \cdot \mathrm{m}^{-2}$ ratura, com média de $21,5^{\circ} \mathrm{C}$ no ensaio com a manta RT-26 e de $24,1^{\circ} \mathrm{C}$ nos demais; e a pluviosidade de menor intensidade nos ensaios com as mantas RT-16 e RT-31. A ação conjunta dessas variáveis foi responsável pelo aumento da evaporação da água presente no lodo retido nas mantas, resultando em melhor eficiência nesses ensaios.

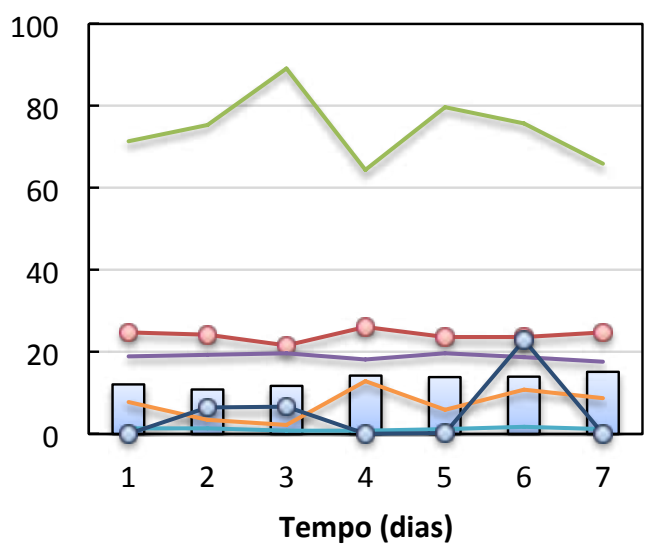

Figura 13 - Dados do teor de sólidos (\%) e as médias diárias das variáveis climáticas para $\mathrm{RT}-16 \mathrm{com}$ TAS $=1,75 \mathrm{~kg} \cdot \mathrm{m}^{-2}$

\section{Legenda}

$\square$ Teor de sólidos (\%)
—— Temperatura $\left({ }^{\circ} \mathrm{C}\right)$
- Umidade $(\%)$
— Orvalho $\left({ }^{\circ} \mathrm{C}\right)$
- Vento $(\mathrm{m} / \mathrm{s})$
- Radiação solar $\left(100 \mathrm{KJ} / \mathrm{m}^{2}\right)$
$\multimap$ Pluviosidade $(\mathrm{mm})$


As Figuras 15, 16 e 17 apresentam os resultados diários obtidos para o teor de sólidos e as variáveis climáticas avaliados para os geotêxteis RT-26, RT-16 e RT-31, respectivamente, no ensaio com TAS de 3,5 $\mathrm{kg} \cdot \mathrm{m}^{-2}$. A ocorrência de precipitação distribuída entre as 18:00 h do quinto dia e às 03:00 h do sexto dia do ensaio com a manta RT-26 (Figura 15) resultou numa redução do teor de sólidos totais. Isso também foi notado para o sétimo dia considerando-se os geotêxteis RT-16 e RT-31 (Figuras 16 e 17), onde o mesmo foi submetido a um volume de chuva distribuída entre às 01:00 h e às 07:00 h.

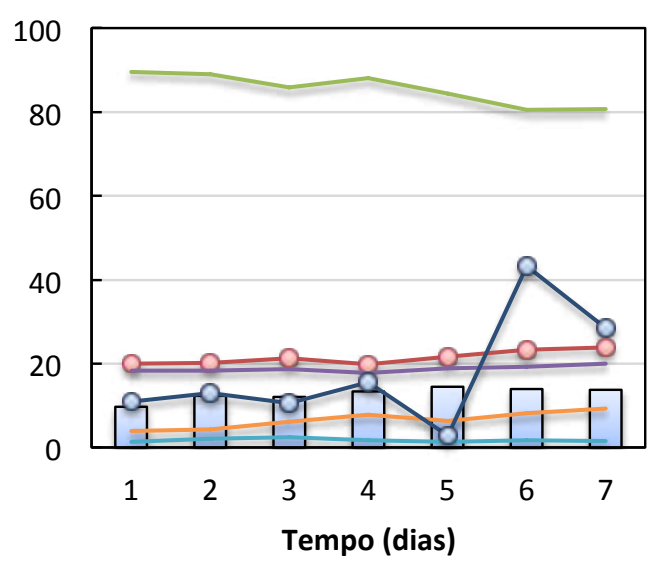

Figura 15 - Dados do teor de sólidos (\%) e médias diárias das variáveis climáticas para RT-26 com TAS $=3,5 \mathrm{~kg} \cdot \mathrm{m}^{-2}$

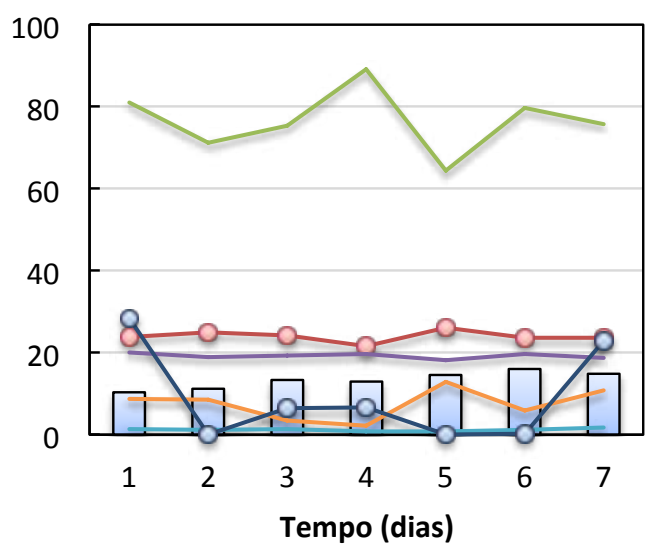

Figura 14 - Dados do teor de sólidos (\%) e médias diárias das variáveis climáticas para RT-31 com TAS $=3,5 \mathrm{~kg} \cdot \mathrm{m}^{-2}$
Ainda é possível notar que em alguns dias, mesmo não havendo precipitação nas últimas $24 \mathrm{~h}$ anteriores ao horário da coleta, o teor de sólidos foi menor que o dia anterior. A ação conjunta das variáveis climáticas pode ter sido responsável por essa redução, como o aumento de umidade, orvalho e baixa velocidade do vento, uma das principais variáveis no processo, pois a perda de umidade do lodo para o ar atmosférico é possível com a troca de ar, e também com a radiação solar, capaz de fornecer energia térmica para a água contida no lodo, facilitando sua evaporação.

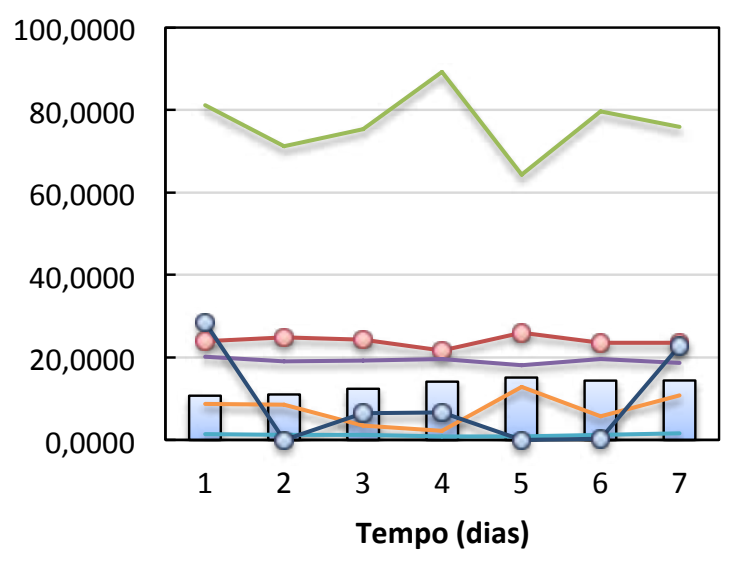

Figura 16 - Dados do teor de sólidos (\%) e médias diárias das variáveis climáticas para $\mathrm{RT}-16$ com TAS $=3,5 \mathrm{~kg} \cdot \mathrm{m}^{-2}$

\section{Legenda}

$\square$ Teor de sólidos $(\%)$
—-Temperatura $\left({ }^{\circ} \mathrm{C}\right)$
— Umidade $(\%)$
$—$ Orvalho $\left({ }^{\circ} \mathrm{C}\right)$
$—$ Vento $(\mathrm{m} / \mathrm{s})$
$\longrightarrow$ Radiação solar $\left(100 \mathrm{KJ} / \mathrm{m}^{2}\right)$
$\multimap$ Pluviosidade $(\mathrm{mm})$


Os resultados diários obtidos para o teor de sólidos e as variáveis climáticas no ensaio com TAS de 7,0 kg.m-2. As Figuras 18, 19 e 20 apresentam os resultados diários obtidos para o teor de sólidos e as variáveis climáticas avaliados para os geotêxteis RT26, RT-16 e RT-31. Da mesma forma que nos ensaios anteriores, os resultados da fase de secagem para essa TAS apresentaram teores de sólidos semelhan-

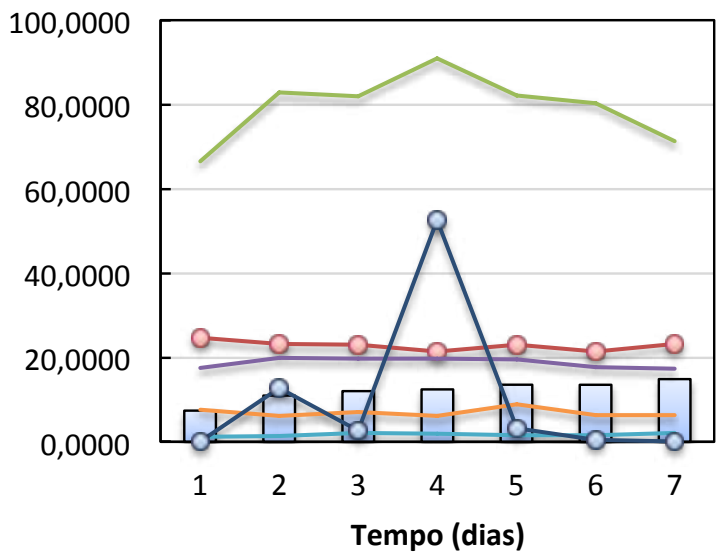

Figura 18 - Dados do teor de sólidos (\%) e médias diárias das variáveis climáticas para RT-26 com TAS = 7,0 kg. $\mathrm{m}^{-2}$

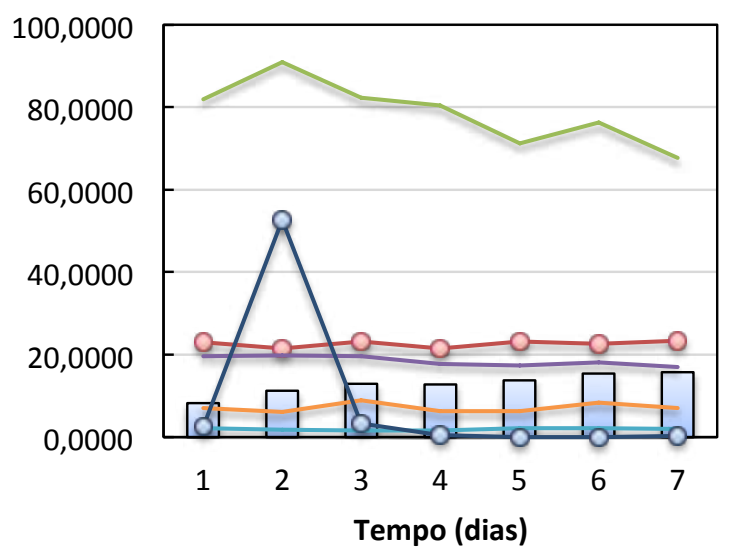

Figura 20 - Dados do teor de sólidos (\%) e médias diárias das variáveis climáticas para $\mathrm{RT}-31 \mathrm{com}$ TAS $=7,0 \mathrm{~kg} \cdot \mathrm{m}^{-2}$ tes, sendo de $14,9 \%, 14,8 \%$ e $15,7 \%$ para as mantas RT-26, RT-16 e RT-31, respectivamente. Até o terceiro dia da fase de secagem, as condições climáticas favoreceram a perda de água do lodo, porém houve um retardo do percentual de sólidos no quarto dia, em virtude do evento de $52,6 \mathrm{~mm}$ de chuva distribuída entre as 13:00 h e as 18:00 h do dia anterior e entre as 00:00 h e as 01:00 h do dia da coleta.

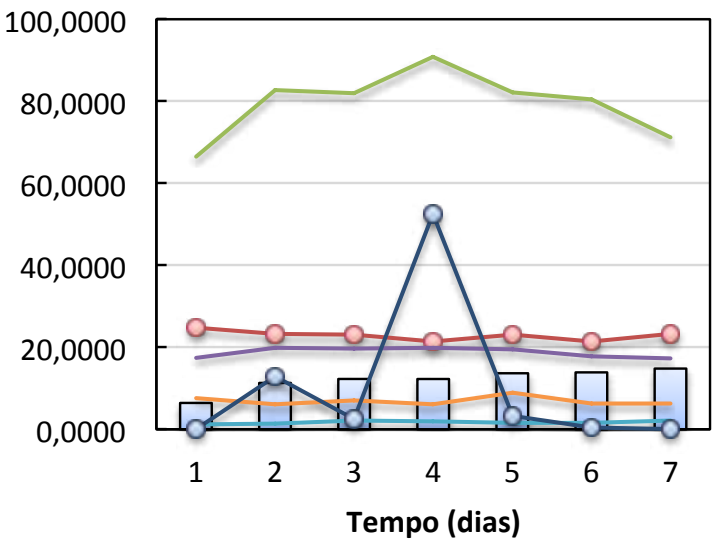

Figura 19 - Dados do teor de sólidos (\%) e médias diárias das variáveis climáticas para $\mathrm{RT}-16 \mathrm{com}$ TAS $=7,0 \mathrm{~kg} \cdot \mathrm{m}^{-2}$

\section{Legenda}

$\square$ Teor de sólidos (\%)
- Temperatura $\left({ }^{\circ} \mathrm{C}\right)$
- Umidade $(\%)$
- Orvalho $\left({ }^{\circ} \mathrm{C}\right)$
- Vento $(\mathrm{m} / \mathrm{s})$
- Radiação solar $\left(100 \mathrm{~kJ} / \mathrm{m}^{2}\right)$
$\multimap$ - Pluviosidade $(\mathrm{mm})$


A etapa de desidratação do lodo foi dificultada em todos os ensaios, uma vez que a ação conjunta das condições climáticas não favoreceu a eficiência da mesma. Dentre essas, destaca-se a alta umidade, responsável pelo retardo do processo de transferência de água para o meio, a ocorrência de chuvas, a baixa ação dos ventos e também o orvalho e a radiação solar.

Análises da secagem de lodo proveniente de ETAs em diversos estudos realizados sob condições climáticas mais favoráveis à desidratação apontaram a eficiência na remoção de sua umidade, tendo como resultados até na ordem de $90 \%$ de sólidos totais, comprovando, assim, o desempenho do leito de drenagem para a redução de volume (BARROSO, 2007; ACHON et al., 2008; SANTOS, 2012; KURODA, 2013).

\section{CONCLUSÕES}

Os resultados obtidos na fase de drenagem dos sistemas de Leito de Drenagem, compostos pelos geotêxteis RT-26, RT-16 e RT-31, em todas as TAS avaliadas $\left(1,75 \mathrm{~kg} \cdot \mathrm{m}^{-2}, 3,5 \mathrm{~kg} \cdot \mathrm{m}^{-2}\right.$ e 7,0 kg.m $\left.{ }^{-2}\right)$ evidenciaram que, nos primeiros 15 minutos, o volume drenado e os valores de turbidez e cor (aparente e verdadeira) são significativamente maiores do que aqueles obtidos em tempos posteriores preestabelecidos.

Ao se comparar o desempenho entre as mantas geotêxteis submetidas à mesma TAS no sistema, observou-se que o drenado coletado nos primeiros 15 minutos do LD constituído pela manta geotêxtil RT-31 foi o que apresentou, em média, menor turbidez, já que este possui propriedades hidráulicas (abertura aparente e permissividade) que favorecem a melhor qualidade de drenado. Foi verificado também que a taxa de aplicação de sólidos interfere no comportamento drenante do geotêxtil.

Os parâmetros avaliados nos drenados coletados apresentaram valores acima dos padrões estabelecidos pela Resolução Conama n 430/2011 e
Deliberação Normativa Conjunta $n^{\circ} 01 / 2008$, do Copam/CERH, e, portanto, necessitam de um tratamento posterior, evitando impactos negativos nos cursos d'água.

Durante a fase de secagem do lodo retido na manta, observou-se a importância da ação conjunta das variáveis climatológicas (temperatura, umidade ambiente, orvalho, velocidade do vento, radiação solar e pluviosidade) na aceleração ou retardamento do processo de desidratação do lodo. Neste trabalho, foi visto que o teor de sólidos do lodo durante o processo de secagem não ultrapassou $20 \%$, em razão do contexto climatológico, que não contribuiu de forma efetiva na evaporação da água presente na torta. Entretanto, a vantagem desse tipo de sistema em relação aos leitos de secagem convencionais está mais relacionada com a etapa de drenagem em que a qualidade do drenado é superior e, considerando-se escala real, as áreas de implantação podem ser menores em função das elevadas TAS possíveis. Ressalta-se que devem ser conduzidos experimentos com esse tipo de lodo em situações climáticas mais favoráveis, de forma que seja possível avaliar também a influência das características do lodo na eficiência final da fase de secagem.

\section{REFERÊNCIAS}

ACHON, C. L. et al. Leito de Drenagem: Sistema Natural para Redução de Volume de Lodo de Estação de Tratamento de Água. Engenharia Sanitária e Ambiental, São Paulo, v.13, n. 1, p. 54 - 62, 2008. ASSOCIAÇÃO BRASILEIRA DE NORMAS TÉCNICAS. NBR 10.664: Águas - Determinação de resíduos (sólidos) - Método gravimétrico. Rio de Janeiro, 1989.

NBR 10.004: Resíduos sólidos: Classificação. Rio de Janeiro, 2004.

BARROSO, M. M. Influência das micro e macro propriedades dos lodos de Estações de Tratamento de Águas no desaguamento por Leito de Drenagem. 2007. 249 f. Tese (Doutorado em Hidráulica e Saneamento) - Escola de Engenharia de São Carlos, Universidade de São Paulo, São Carlos, 2007.

BIDIM. Soluções em geossintéticos. Especificação Técnica Geotêxtil Bidim. Disponível em: < http://www.bidim.com.br/>. Acesso em: 26 set. 2014. 
CONSELHO NACIONAL DO MEIO AMBIENTE. Resolução n 430, de 13 de maio de 2011. Dispõe sobre as condições e padrões de lançamento de efluentes, complementa e altera a Resolução n 357, de 17 de março de 2005, do Conselho Nacional do Meio Ambiente - CONAMA. Lex: Diário Oficial da União, n. 92, p. 89 - 96, 2011.

CONSELHO ESTADUAL DE POLÍTICA AMBIENTAL (COPAM), CONSELHO ESTADUAL DE RECURSOS HÍDRICOS DO ESTADO DE MINAS GERAIS (CERH-MG). Deliberação Normativa Conjunta COPAM/ CERH-MG n01, de 05 de maio de 2008. Dispões sobre a classificação dos corpos de água e diretrizes ambientais para o seu enquadramento, bem como estabelece as condições e padrões de lançamento de efluentes, e dá outras providências. Lex: Diário do Executivo - “Minas Gerais”, 2008.

CORDEIRO, J. S. Processamento de lodos de Estações de Tratamento de Água (ETA's). In: ANDREOLLI, C. V. (Coord.). Resíduos sólidos do saneamento: processamento, reciclagem e disposição final. Capítulo 9. Rio de Janeiro: ABES, 2001. 282 p. (Projeto PROSAB).

FONTANA, A. O. Sistema de Leito de Drenagem e Sedimentador como solução para a redução de volume de lodo de Decantadores e Reuso de água de Lavagem de Filtros - Estudo de Caso - ETA Cardoso. 2004. 161 f. Dissertação (Mestrado em Engenharia Urbana) - Centro de Ciências Exatas e de Tecnologia, Universidade Federal de São Carlos, São Carlos. 2004.

FONTANA, A. O. et al. Redução de lodo digerido gerado em lagoas de estabilização com utilização de leito de drenagem. In: CONGRESSO BRASILEIRO DE ENGENHARIA SANITÁRIA E AMBIENTAL, 24. Anais ... Belo Horizonte, 2007.

KURODA, E. K. et al. Drenagem/secagem de lodo de decantadores de ETAs em manta geotêxtil. Revista DAE, São Paulo, n. 194, p. 24-34, 2013
LOPES, L. N. A. et al. Avaliação do desaguamento de lodo de ETA em leito de secagem. In: CONGRESSO BRASILEIRO DE ENGENHARIA SANITÁRIA E AMBIENTAL, 23., 2005, Campo Grande. Anais ... Campo Grande, 2005.

MORTARA, F. C. Utilização de leitos de drenagem no desaguamento de lodos anaeróbios. 2011. 241 f. Dissertação (Mestrado em Engenharia) - Departamento de Engenharia Hidráulica e Ambiental, Universidade de São Paulo, São Paulo, 2011.

PERES, S. D. Técnicas aplicadas ao tratamento e redução dos efluentes líquidos de uma empresa de saneantes domissanitários. 2005. 112 f. Dissertação (Mestrado Profissionalizante em Engenharia Ambiental e Tecnologias Limpas) - Escola de Engenharia, Universidade Federal do Rio Grande do Sul, Porto Alegre, 2005.

SANTOS, B. Avaliação da Aplicação do Sistema de Leito de Drenagem como tratamento do Lodo da Estação de Tratamento de Água Bom Jardim em Uberlândia-MG. 2012. 98 f. Dissertação (Mestrado em Engenharia Civil) - Faculdade de Engenharia Civil, Universidade Federal de Uberlândia, Uberlândia. 2012.

SILVEIRA, C. et al. Desaguamento de lodo de Estações de Tratamento de Águas - ETAs por LD com mantas geotêxteis - escala reduzida. Anais ... Porto Alegre: $26^{\circ}$ Congresso Brasileiro de Engenharia Sanitária e Ambiental, 2011.

SILVEIRA, C. Desaguamento de lodo de Estações de tratamento de águas por leito de drenagem/secagem com manta geotêxtil. 2012. 137 f. Dissertação (Mestrado em Engenharia de Edificações e Saneamento) - Centro de Tecnologia e Urbanismo, Universidade Estadual de Londrina, Londrina. 2012. 